\title{
Two-way transparency
}

For several years there have been complaints about the transparency of the Australian drug regulatory system. Pharmaceutical companies complain about the transparency of decisions to approve or reject a product for marketing or subsidy, while clinicians complain that they cannot access the data used to make those decisions.

The Pharmaceutical Benefits Advisory Committee has been working with the pharmaceutical industry to address some of these criticisms. Greater transparency of the operation of the Pharmaceutical Benefits Scheme (PBS) was also a key feature of the free trade agreement between Australia and the USA.

While the pharmaceutical industry has achieved some of its goals, much of the clinical data it provides to government remains secret. The Editorial Executive Committee believes that clinical information which could be used to help patients should not be kept as 'commercial-in-confidence'.1,2

In view of the pharmaceutical industry's interest in greater transparency, the Editorial Executive Committee has been inviting companies to supply the information that supported the approval of their products in Australia. This information can then be used in the preparation of the New Drugs section of Australian Prescriber and enhances the evidence base for these comments.

While there has been a range of responses (Table 1), the Editorial Executive Committee is pleased that some companies are willing to provide information for independent review. Companies have also been supplying information to assist the National Prescribing Service in preparing its RADAR review of new listings on the PBS. We hope this is the beginning of a trend which will lead to increased transparency in drug regulation.

\section{References}

1. Eadie M. The secrecy of drug regulatory information. Aust Prescr 2002;25:78-9.

2. Marley J. Cost-effectiveness: the need to know. Aust Prescr 1996;19:58-9.

Table 1

T-Score: Pharmaceutical company responses to requests for clinical evaluation data July 2003 - June 2005

Company

Drug

Manufacturer provided all requested information $\mathbf{T} T \mathbf{T}$

Abbott

Bristol-Myers Squibb

adalimumab

Ferring

Gilead Sciences

Lundbeck

Pfizer

Roche

Specialites Septodont

atazanavir

carbetocin

adefovir dipivoxil

escitalopram

eplerenone

enfuvirtide

articaine

Manufacturer provided some data $\mathbf{T} \mathbf{T}$

CSL Ltd

bivalirudin

Eli Lilly

atomoxetine

Eli Lilly

pemetrexed

Genzyme

Laboratoires Fournier

Merck Sharp \& Dohme

Novartis

Schering

Servier

agalsidase beta

fenofibrate

aprepitant

ketotifen hydrogen fumarate

iloprost

strontium ranelate

Manufacturer had no objection to providing data but did not actually provide it $\mathbf{T}$

AstraZeneca

Genzyme

Novartis

Orphan

Pharmion

Pfizer

Serono rosuvastatin

laronidase-rch

lumiracoxib

treprostinil

thalidomide

pregabalin

efalizumab
Company

Drug

Manufacturer declined to supply data

GlaxoSmithKline

ropinirole

Janssen Cilag

Novo Nordisk

norelgestromin and ethinyloestradiol

Schering insulin detemir disodium gadoxetate

Manufacturer did not respond to request $\mathrm{X}$

Amgen

cinacalcet

ANSTO Radiopharmaceuticals iobenguane [ $\left.{ }^{123} \mathrm{i}\right]$ sulphate

Aventis Pasteur

Aventis Pharma inactivated cholera vaccine

Baxter Healthcare insulin glulisine

Baxter Healthcare iron sucrose

human protein $\mathrm{C}$ (plasma derived)

Baxter Healthcare

Biogen

Bracco

Douglas

Gilead Sciences

GlaxoSmithKline

Novartis

Novartis

Pfizer

Solvay amotosalen

alefacept

gadobenate dimeglumine poractant alfa emtricitabine fosamprenavir everolimus darifenacin hydrobromide tolterodine tartrate moxonidine 